\title{
Thermal and hydraulic effects of coke deposit in hydrocarbon pyrolysis process.
}

\author{
N. Gascoin ${ }^{1}$, G. Abraham², P. Gillard ${ }^{3}$ \\ University of Orléans, PRISME, 63, avenue de Lattre de Tassigny-18000 Bourges, France
}

Fuel pyrolysis can be of benefit for regenerative cooling techniques due to its endothermic effect in ensuring the thermal resistance of hypersonic vehicles and structures. Among pyrolysis species production, there is that of coke formation. A numerical code is used in this paper to investigate the related phenomena, based on two experiments using Titanium (Ti) and Stainless Steel (SS) reactors, which present different pyrolysis rates under similar operating conditions.. The absence of effect of the reactor's physical properties on the pyrolysis is demonstrated. The thermal insulation effect by coke deposit is proved to have a negligible impact on the system. The clogging of the reactor found experimentally is confirmed numerically at the same time. The carbon deposit thickness reaches the value of the reactor's inner radius: $\mathbf{2 . 1 7 5} \mathbf{~ m m}$. The corresponding reduction of flow cross-section modifies the Reynolds number, the residence time (decreased by a factor of 4) and the absorbed energy (reduction by a factor of 3). This last point is responsible for the discrepancies observed experimentally. The coke sticks to the SS reactor and not to the Ti reactor. Consequently, pyrolysis is lower for the SS case than for the Ti case under similar furnace temperature setups.

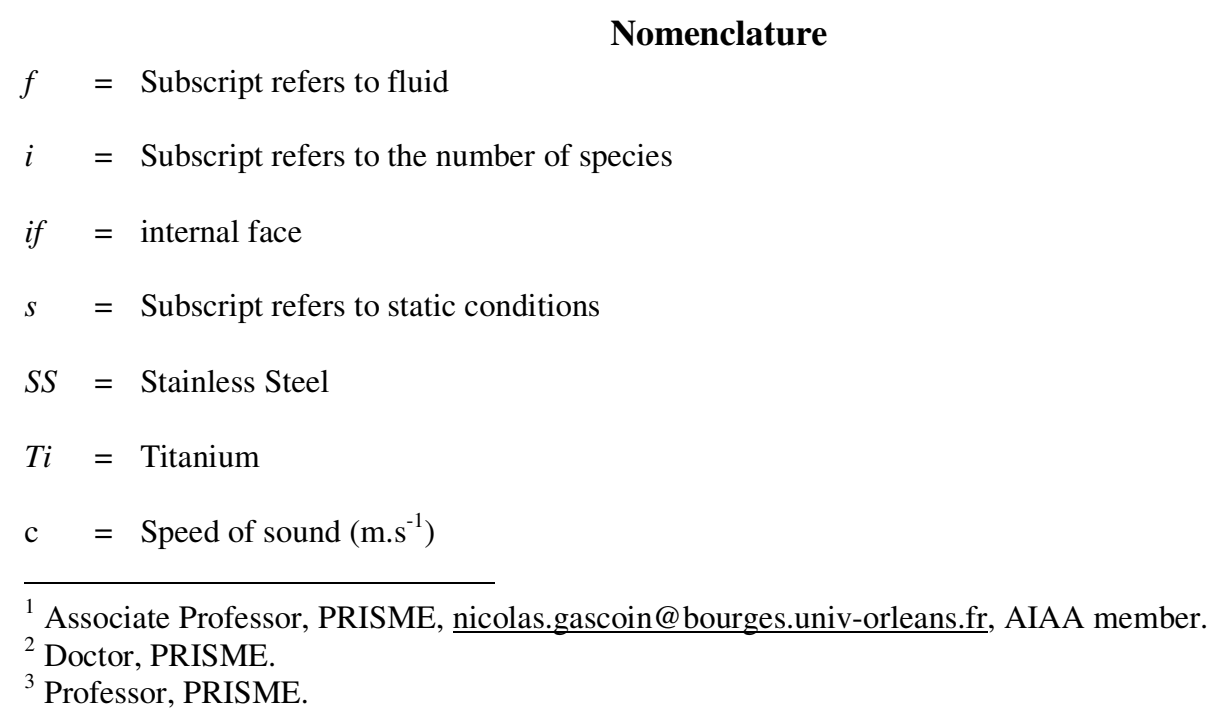




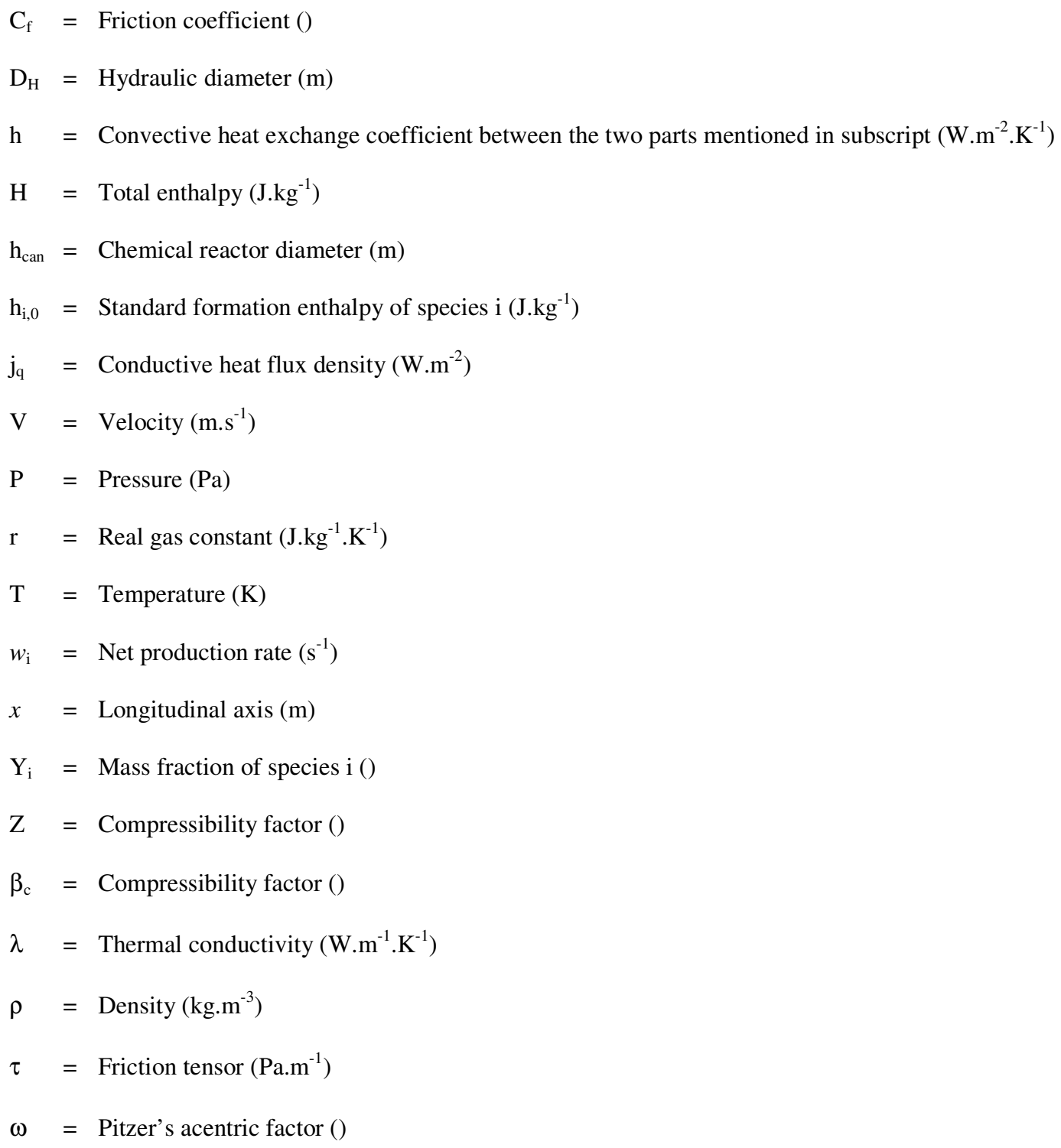

\section{Introduction}

Co ensure the thermal resistance of hypersonic structures, active cooling techniques are of interest, notably in case of regenerative methods to be applied on the SCRamjet engine [1],[2]. Some similarities can be found to ablation studies [3], [4]. Using the fuel as a coolant decreases the wall temperature because of counter-flow heat exchanges, of endothermic pyrolysis and of possible internal convection in porous media with related film cooling [5],[6],[7]. The permeable structure is generally made of Ceramic Matrix Composites. Some research also focuses on the development of metallic hollow spheres whose porosity is well defined and homogeneous [8]. Kerosene surrogates (such as dodecane) are often 
considered experimentally to investigate fuel pyrolysis because of their simple chemical composition [9]. During the pyrolysis of initial alkane fuel, the production of highly hydrogenated compounds (particularly hydrogen and methane) is accompanied by carbon deposits [10],[11]. Coke formation has been largely studied in open literature [12]. Several ways exist (oxidation, pyrolysis, catalysis, condensation) and the carbon deposits are found under different forms (filamentous, aggregates) [13]. Some numerical mechanisms take the coke into account and they allow the detailed chemical reactions involved in its formation [14] to be investigated. These kinetic schemes obviously depend on the initial fuel composition (methane, biofuel, petroleum) [15]-[18]. Such a chemical approach is not sufficient to take the physical effect of the carbon layer into account. A multiphysics investigation is required to understand the relationship between each phenomenon and particularly its effect on the conversion rate [19]. For example, Albright and Marek [19] showed the major effect of residence time and operating time on coke formation and observed its non uniformity along the process.

In this framework, the COMPARER program (COntrol and Measure of PArameters in a REacting stReam) has been launched by MBDA-France and by the University of Orléans (France) [20]. It consists in improving the knowledge on fuel pyrolysis in tubular reactors before extending the work to other configurations (permeable media). A considerable lack of applicable data and knowledge to enable an understanding and prediction of the coke effect on heat and mass transfer in coupled systems has been identified [20]. The RESPIRE code (a French acronym for SCRamjet Cooling with Endothermic Fuel, Transient Reactor Programming) has been developed and has undergone extensive validation since 2004 for this purpose [21]-[23]. It is a one dimensional program able to simulate hypersonic vehicle cooling as well as a single chemical reactor heated by a furnace. It considers an existing detailed dodecane pyrolysis mechanism (1185 reactions, 153 species) [24]. Empirical relationships are used numerically to calculate coke production [9]. Coke formation has been experimentally considered in previous papers because of its non negligible impact (channel clogging, thermal insulation, catalytic effect) [9]. Some empirical laws have been proposed to estimate the carbon quantity on the basis of other acquired signals (methane production or operating parameters) for future real-time onboard applications. Nevertheless, no analyses have been performed to determine or quantify the coke effect on other physical and chemical parameters (conductive heat flux, flow regime, convective heat coefficient). Since these data are difficult to estimate experimentally, the numerical RESPIRE code is used to compute these parameters directly. 
Mohamadalizadeh et al. [25] take coke formation into account through a kinetic mechanism and they observe the time and spatial distributions of the carbon layer thickness. They identify the catalytic part of this coke formation. The surface effect of the reactor is found to be largely smaller than the temperature effect but the authors consider that it has been underestimated. The catalytic effect has been also investigated in industrial plant conditions by Kern and Jess [26] under different operating conditions (length of the process, operating time, temperature setup). The microstructure of the solid material plays a major role. Garcia-Dopico et al. [11] investigate the contact time between the hydrocarbon fuel and the catalyst surface. The deactivation effect is clearly visible since the catalyst activity falls by more than a factor 2 depending on the operating conditions. A finer approach is proposed by Beyne and Froment [27] who quantify coke formation in catalyst and its impact on the resulting chemical composition. Few numerical CFD studies focus on coke formation with detailed chemistry. The works are generally based on experiments or those numerically oriented use 0-D simulations. Guo and Tang [28] consider 2-D CFD simulation but the chemistry is not considered precisely and their work does not focus on the prediction of coke formation but rather on the gas flow through the coke process. Manafzadeh et al. [29] conducted 1-D transient computations, with semi-detailed mechanism (22 reactions), of coke formation and deposition in an industrial plant with an inlet multi-component fuel mixture up to $1139 \mathrm{~K}$ at $0.16 \mathrm{MPa}$. The coke thickness is given as a function of time and space. The pressure decrease due to the coke thickness increase is presented and it is directly related to the non uniform layer. Finally, Souza et al. [30] also use CFD simulation to predict coke formation in case of petroleum pyrolysis. The effect of the flow regime on the fluid temperature is investigated and the coke formation is highly reduced in case of turbulent flow. Several other interesting studies can be mentioned but none of them account simultaneously for fluid flow, heat transfer, detailed chemistry and catalytic effect. Furthermore, a weak point related to catalytic studies with fuel degradation is that the differences resulting from two materials are generally linked to the chemical nature of the solid surface only. The physical properties (heat capacity, density, thermal conductivity) are not explicitly considered whereas they can be of strong effect. Indeed, in energy equations applicable to solids, thermal conductivity appears in the numerator and heat capacity and density in the denominator when written on the right hand side. Thus, these properties directly impact the transient heat transfer in solids but also the heat flux to be exchanged under steady-state regimes with the fluid because of the conservation of incoming heat fluxes in heated systems. 
For this reason, a step by step methodology with a splitting strategy for physical phenomena is applied in this paper to differentiate the parameters. The aim of the present work is to contribute to the analysis of such complex multi-physics coupled systems and to ensure the proper simulation of the experimental process using the RESPIRE code. In addition, improving the fundamental knowledge of coke formation and its effect should help to manage it in industrial and lab contexts. Two similar experimental test cases are considered as a reference for this study: one with a stainless steel (SS) tubular reactor and one with a Titanium (Ti) reactor. They are repeated with RESPIRE to analyze the origin of the differences.

\section{Material and methods}

RESPIRE is presented briefly in section II-A. Further information can be found in the work of Gascoin et al. [22]. Deep validations of thermal, hydraulic and chemical aspects have been conducted under transient and stationary conditions for analytical, numerical and experimental cases [5], [9],[21],[22]. The COMPARER test bench is presented in section II-B with the related experimental methodology of pyrolysis tests.

\section{A. Simulation of the chemical reactor}

Due to the one dimensional structure of the RESPIRE code, all variables are constant on a crosssection of the fluid or material. The fluid is considered to be homogeneous on each slice along the flow. It is treated as an average single phase flow but possibly multi-species. However, the phase or the state of the fluid can be non uniform along the flow. The spatial step is of the order of $5.10^{-3} \mathrm{~m}$ and the time step is automatically adjusted with respect to the flow velocity to ensure the numerical stability conditions. An average temperature is computed for each wall, considering radiative, convective and conductive heat fluxes. The temperatures of the two faces of each wall are then deduced.

The velocity of the fluid $V_{f}$ is determined by the momentum equation (Eq. (1)) and its enthalpy $H_{f}$ by the energy equation (Eq. (2)). The frictions are computed with Eq. (3) and they are based on semiempirical correlations [9]. The kerosene is modeled by n-dodecane, for which a very detailed pyrolysis mechanism is available (1185 reactions and 153 species) [24]. The chemical reaction set and the corresponding reaction rate coefficients are available on request from the original authors either Dahm et al. [24] or more recently Herbinet et al. [31]. The net production rates $\left(w_{i}\right)$ of species $i$ are determined 
using the pyrolysis mechanism. The transport equation (Eq. (4)) is solved for every chemical species except for dodecane which serves as balance of the mass fractions sum to unity.

$$
\begin{gathered}
\frac{\partial\left(\rho_{f} \cdot V_{f}\right)}{\partial t}+\frac{\partial\left(\rho_{f} \cdot V_{f}^{2}\right)}{\partial x}=-\frac{\partial P_{s f}}{\partial x}+\frac{\partial \tau}{\partial x} \\
\frac{\partial\left(\rho_{f} \cdot H_{f}\right)}{\partial t}+\frac{\partial\left(\rho_{f} \cdot V_{f} \cdot H_{f}\right)}{\partial x}=\left(1-\beta_{c} \cdot T_{s f}\right) \frac{\partial P_{s f}}{\partial t}+\frac{\partial}{\partial x}\left(-j_{q}+V_{f} \cdot \tau\right)+\rho \cdot \sum_{\text {species }} h_{i, 0} \cdot w_{i} \\
+\frac{1}{h_{c a n}} h_{i f-f}\left(T_{i f}-T_{f}\right) \\
\frac{\partial \tau}{\partial x}=-\frac{C_{f}}{2} \times \rho \cdot V_{f}^{2} \times \frac{4}{D_{H}} \\
\frac{\partial\left(\rho_{f} \cdot Y_{i}\right)}{\partial t}+\frac{\partial\left(\rho_{f} \cdot V_{f} \cdot Y_{i}\right)}{\partial x}=\rho_{f} w_{i}
\end{gathered}
$$

where $\rho_{f}$ is the fluid density, $t$ the time, $x$ the abscissa, $P_{s f}$ the static pressure, $D_{H}$ the hydraulic diameter, $C_{f}$ the friction coefficient, $\quad \beta_{c}=1 / \rho \times \partial \rho /\left.\partial T\right|_{P}$ the thermal expansion coefficient, $j_{q}=-\lambda_{f} \cdot \operatorname{grad}\left(T_{f}\right)$ the thermal conduction term, $\lambda_{f}$ the thermal conductivity, $h_{i, 0}$ the standard enthalpy of species, $h_{c a n}$ the channel height, $h_{i f-f}$ the convective exchange coefficients between the cold wall and internal face respectively with fluid, $T_{i f}$ the reactor wall temperature in contact with the fluid and $Y_{i}$ the mass fractions of the $i$ species.

In case of coking activity, a solid deposit appears along the reactor. This is taken into account through the reduction of the hydraulic diameter $\left(D_{H}\right.$ in Eq. 3 for example) and as an additional sink term in Navier-Stokes equations and in Eq. 3 [22]. The thermal conductivity of the reactor wall is thus modified accordingly using a series law considering both that of pure deposited carbon and that of the original reactor material with their respective thicknesses. On the basis of previous experimental work on carbon deposition, the coking rate is tabulated as a function of residence time (Fig. 8 of the work of Gascoin et al. [10]). Considering a density of $1900 \mathrm{~kg} \cdot \mathrm{m}^{-3}$, the carbon deposit layer thickness is deduced and it increases as a function of the simulation time. A criterion is applied because the coke does not appear before a given level of pyrolysis and heat flux. No coke formation is considered until the mathematical product of "mean process temperature" by "simulation time" by "residence time" exceeds $10^{8} \mathrm{~K} . \mathrm{s}^{2}$ (in conformity with Fig. 10 of the work of Gascoin et al. [10]). 
Dynamic viscosity and thermal conductivity are computed using the method of Guo et al. [32]. The method uses the Peng Robinson Equation of State. JANAF-type polynomials are used to calculate the heat capacity of each species. An equation of state $(P / \rho=Z . r . T)$ is used to determine the density considering the compressibility factor: $Z=Z^{+(0)}+\omega \cdot Z^{+(1)}$ where $\omega=\left(0.2901-Z_{c}\right) / 0.0879$ the Pitzer's acentric factor. The Lee-Kesler tables are needed for $Z^{+(0)}$ and $Z^{+(1)}$ determination and for corrections of the heat capacity as a function of temperature and pressure. Fluid pressure is determined by the use of Bulk Modulus $\beta=\partial P /(\partial \rho / \rho)$ with $\beta=\rho . c^{2}$ ( $c$ the speed of sound).

\section{B. Experimental test bench}

The COMPARER test facility [9] is a high pressure and high temperature experimental bench (Figure 1) which enables the study of reactive flows in configurations, which are representative of real in-flight conditions. The bench is composed of a high pressure pump ( $\left.8 \mathrm{MPa}, 0.5 \mathrm{~g} . \mathrm{s}^{-1}\right)$ for liquid fuel injection. The fluid is heated in an open tubular reactor $(1 \mathrm{~m}$ long), which is placed inside a $6 \mathrm{~kW}$ furnace (maximum temperature of $1900 \mathrm{~K}$ ). The tubular pyrolysis reactor is composed of an SS or Ti tube (inner diameter of $4.35 \mathrm{~mm}$ ). Numerous sensors (over $10 \mathrm{~K}$-type thermocouples, 3 pressure transducers, 5 flow meters) are connected to a data acquisition system (10 Hz, 16 bits, 48 ways). Physically, the fuel entering the reactor at ambient temperature and high pressure $(6 \mathrm{MPa})$ is heated by internal convection due to the radiative heat flux applied to the reactor. After about $0.3 \mathrm{~m}$, the fuel becomes supercritical. At $0.5 \mathrm{~m}$ from the inlet, it starts to pyrolyse before getting cooled down in the last third of the reactor due to the decreasing border temperature of the furnace. Within $50 \mathrm{~K}$, the fuel reaches the maximum furnace temperature in the centre and the pyrolysis represents only $10 \%$ of the residence time (acceleration of the pyrolysing fluid). A coke formation can be observed in the second half of the reactor. The reactions forming the Poly Aromatic Hydrocarbons are expected in the downstream part of the reactor. 


\section{Gas Chromatograph / Mass Spectrometer}

Bunsen Burner

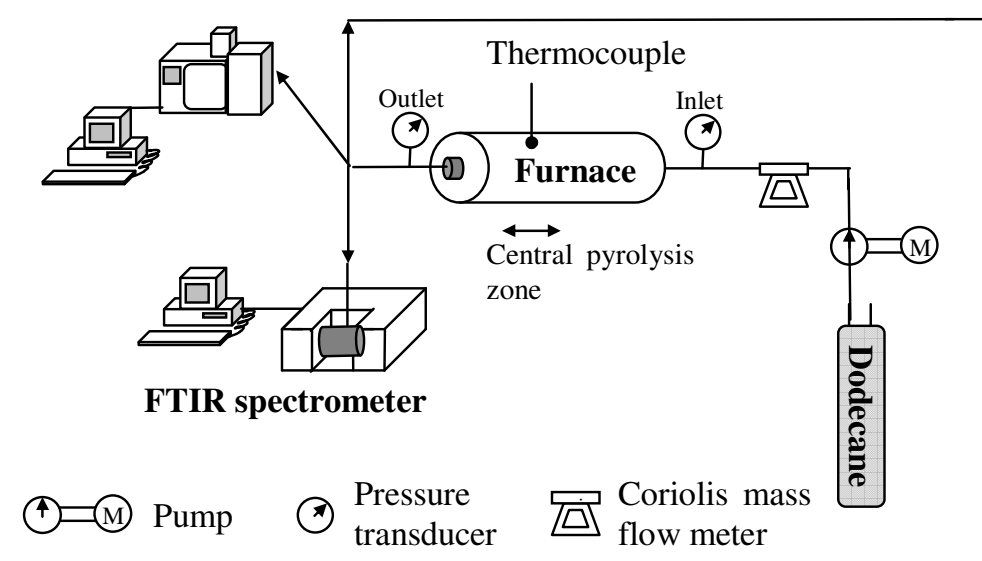

Figure 1. Diagram of the high pressure and temperature pyrolysis bench.

A FTIR spectrometer NICOLET 6700 is available with a quantification method of the pyrolysis products under stationary and transient conditions to enable "real-time" and in-line measures [33],[34]. The pyrolysis tests are conducted with successive stationary isothermal plateaus from $823 \mathrm{~K}$ to $1073 \mathrm{~K}$ at $0.05 \mathrm{~g} . \mathrm{s}^{-1}$. The outlet pressure is regulated at $6 \mathrm{MPa}$ and the inlet pressure is measured. After expansion and cooling of the fluid to atmospheric conditions, the liquid and gas phases are sampled and analysed by Gas Chromatograph and Mass spectrometer (GC/MS).

\section{Results and Discussion}

The numerical results of the two reference cases are first compared with the experiments (section IIIA). The initial conditions of the computations are the ambient conditions and the boundary conditions are the inlet pressure, the mass flow rate and the longitudinal temperature profile of the heating system; all of them experimentally measured. The effect of physical properties depending on the reactor's nature is investigated (section III-B). Coke formation is considered from a thermal point of view - first, alone - to estimate its insulation effect due to thermal resistance (section III-C). The hydraulic effect is then quantified through the decrease of flow cross-section (section III-D). In the following, the titanium case is considered to be the reference since no tests using quartz tubes were possible at the considered operating pressure (6 MPa). The Ti Grade 2 quality (purity over $99.4 \%$ and $\mathrm{O}$ atoms content of less than $0.2 \%$ ) is assumed to present a reduced catalytic effect compared to the Nickel content, for example, of the SS reactor. 


\section{A. Comparison of experimental and numerical results}

The pressure and temperature time line is presented in Figure $2 \mathrm{a}$ and that of mass flow rate is given with the remaining dodecane mass fraction measured at the process outlet by GC/MS (Figure 2b). Three thermal plateaus are performed for the Ti case and four for the SS one. A clogging of the process due to strong coke formation is found at the end of the experiment duration with a pyrolysis rate of close to 100 $\%$. The coking activity is clearly seen through instabilities on the mass flow rate over $5000 \mathrm{~s}$ (Figure $2 \mathrm{~b}$ ). The low oscillations before $5000 \mathrm{~s}$ are due to the "natural" oscillations of the pump. The gas and liquid samples have been analyzed by GC/MS and compared to the Ti and SS cases for successive thermal plateaus (Table 1). The values given in this Table 1 are those found experimentally (in wt.\%) for the 29 measured compounds. The gasification rate determined for each plateau, made by comparing the quantity of liquid pyrolysis products at the outlet divided by initial fuel quantity used at the inlet, is given in wt.\%. The pyrolysis rate (in wt.\%) is defined as the unity minus the dodecane mass fraction measured at the process outlet.

For the same maximum furnace temperature setup (in Kelvin, Table 1), the Ti case presents gasification and pyrolysis rates higher than those of the SS case. The reason for such discrepancies is not clear to the authors and this justifies the present work in order to choose among the several possible assumptions that can made to explain these results. The reason could be the reactor material and the difference of physical properties. The catalytic effect could also be responsible for this chemical activity. The coke layer is another possibility. Indeed, $\mathrm{SS}$ is known to increase the coking activity due to $\mathrm{Ni}$ and $\mathrm{Cr}$ content. The carbon sticks to the reactor and forms agglomerates whereas for the Ti reactor, the carbon is evacuated to the process outlet in the form of dry and fine powder [9]. The coke may form an insulation layer between the SS reactor and the fluid and it can reduce the flow section. Numerical simulations have been conducted in the present study to investigate these possibilities. It can be noted that these computations use the minimum space step to ensure the consistency of the numerical results. Previous

work related to mesh sensitivity analysis can be found in Ref. [9] and the most recent case of experimental validation of the code is available in Ref. [34]. 


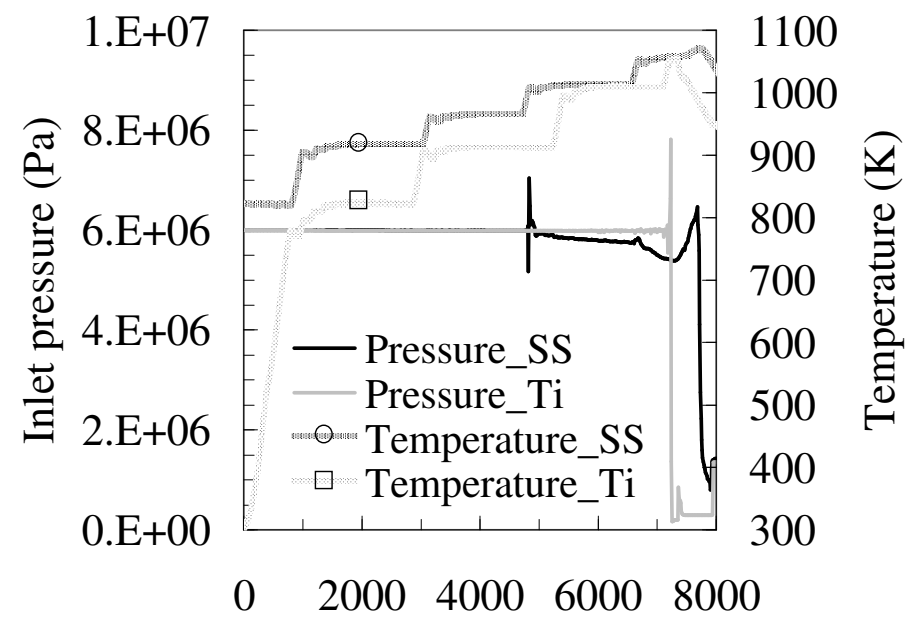

\section{Time (s)}

a)

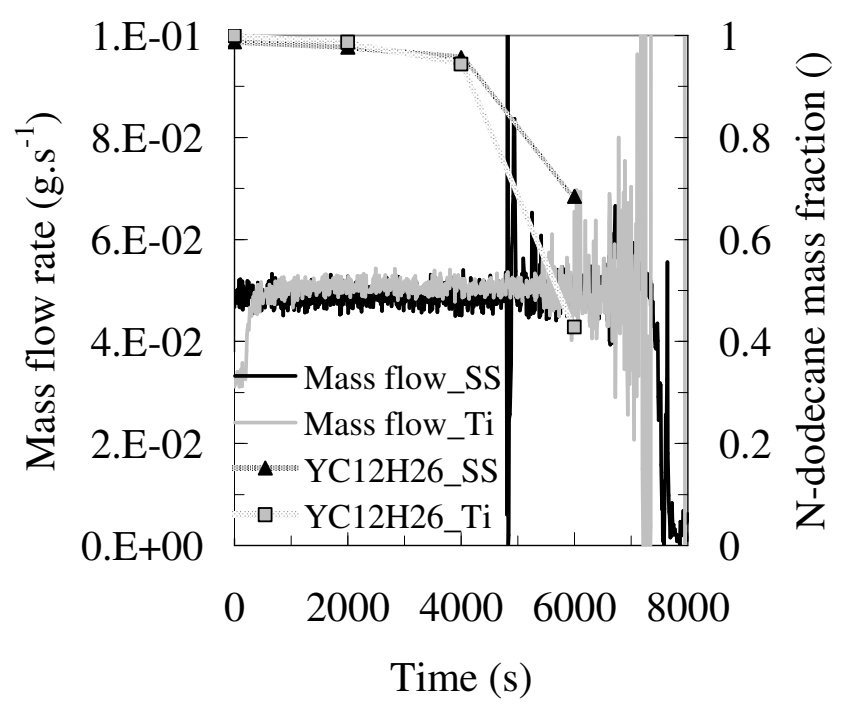

b)

Figure 2. Experimental pressure and temperature conditions of SS and Ti cases (a) with corresponding measured mass flow rate and dodecane mass fraction (b).

Table 1. GC/MS mass fraction (in \%) of pyrolysis products and related gasification and pyrolysis rates (in wt.\%) obtained for different temperatures (in K) using Ti and SS reactors at 6 MPa and 50 mg.s ${ }^{-1}$. 


\begin{tabular}{|c|c|c|c|c|c|c|c|}
\hline Reactor Nature & $\mathrm{Ti}$ & SS & $\mathrm{Ti}$ & SS & SS & $\mathrm{Ti}$ & SS \\
\hline Temperature & \multicolumn{2}{|c|}{822} & \multicolumn{2}{|c|}{912} & 963 & \multicolumn{2}{|c|}{1009} \\
\hline Hydrogene & $0.0 \mathrm{E}+00$ & $0.0 \mathrm{E}+00$ & $1.8 \mathrm{E}-05$ & $1.0 \mathrm{E}-06$ & $1.5 \mathrm{E}-06$ & $6.4 \mathrm{E}-04$ & $2.9 \mathrm{E}-05$ \\
\hline Methane & $0.0 \mathrm{E}+00$ & $0.0 \mathrm{E}+00$ & $2.6 \mathrm{E}-03$ & $3.5 \mathrm{E}-04$ & $4.2 \mathrm{E}-04$ & $5.1 \mathrm{E}-02$ & $1.5 \mathrm{E}-02$ \\
\hline Ethylene & $0.0 \mathrm{E}+00$ & $0.0 \mathrm{E}+00$ & $3.6 \mathrm{E}-03$ & 8.3E-04 & 9.3E-04 & 4.3E-02 & $2.9 \mathrm{E}-02$ \\
\hline Ethane & $0.0 \mathrm{E}+00$ & $0.0 \mathrm{E}+00$ & $1.1 \mathrm{E}-02$ & $1.5 \mathrm{E}-03$ & 1.6E-03 & $1.1 \mathrm{E}-01$ & 4.4E-02 \\
\hline Propylene & $0.0 \mathrm{E}+00$ & $0.0 \mathrm{E}+00$ & 7.7E-03 & $1.5 \mathrm{E}-03$ & 2.1E-03 & $1.1 \mathrm{E}-01$ & $5.9 \mathrm{E}-02$ \\
\hline Propane & $0.0 \mathrm{E}+00$ & $0.0 \mathrm{E}+00$ & $8.5 \mathrm{E}-03$ & $1.5 \mathrm{E}-03$ & $2.0 \mathrm{E}-03$ & $1.0 \mathrm{E}-01$ & 4.7E-02 \\
\hline Butene & $0.0 E+00$ & $0.0 \mathrm{E}+00$ & $2.8 \mathrm{E}-03$ & $5.9 \mathrm{E}-04$ & $1.2 \mathrm{E}-03$ & $4.8 \mathrm{E}-02$ & $3.2 \mathrm{E}-02$ \\
\hline Butane & $0.0 \mathrm{E}+00$ & $0.0 \mathrm{E}+00$ & $3.0 \mathrm{E}-03$ & $5.2 \mathrm{E}-04$ & 1.1E-03 & $6.2 \mathrm{E}-02$ & 3.0E-02 \\
\hline Pentene & $0.0 E+00$ & $0.0 \mathrm{E}+00$ & 3.4E-05 & $2.5 \mathrm{E}-06$ & 7.4E-05 & $1.0 \mathrm{E}-03$ & $2.8 \mathrm{E}-03$ \\
\hline Pentane & $0.0 \mathrm{E}+00$ & $0.0 \mathrm{E}+00$ & $6.6 \mathrm{E}-05$ & 3.0E-06 & $3.2 \mathrm{E}-05$ & 2.7E-03 & $2.5 \mathrm{E}-03$ \\
\hline Hexene & 6.3E-04 & $0.0 \mathrm{E}+00$ & $6.9 \mathrm{E}-04$ & $0.0 \mathrm{E}+00$ & $0.0 \mathrm{E}+00$ & $1.5 \mathrm{E}-03$ & $0.0 \mathrm{E}+00$ \\
\hline Hexane & $3.5 \mathrm{E}-04$ & $7.5 \mathrm{E}-04$ & 1.6E-03 & $9.5 \mathrm{E}-04$ & 1.4E-03 & 2.4E-02 & $1.8 \mathrm{E}-02$ \\
\hline Heptene & $0.0 \mathrm{E}+00$ & $0.0 \mathrm{E}+00$ & $0.0 \mathrm{E}+00$ & $0.0 \mathrm{E}+00$ & $0.0 \mathrm{E}+00$ & $0.0 \mathrm{E}+00$ & $0.0 \mathrm{E}+00$ \\
\hline Heptane & $0.0 \mathrm{E}+00$ & 2.0E-04 & $0.0 \mathrm{E}+00$ & $2.0 \mathrm{E}-04$ & $1.8 \mathrm{E}-04$ & $0.0 \mathrm{E}+00$ & $1.2 \mathrm{E}-04$ \\
\hline Octene & $0.0 \mathrm{E}+00$ & $0.0 \mathrm{E}+00$ & $0.0 \mathrm{E}+00$ & $1.9 \mathrm{E}-05$ & $0.0 \mathrm{E}+00$ & $0.0 \mathrm{E}+00$ & $2.1 \mathrm{E}-05$ \\
\hline Octane & $0.0 \mathrm{E}+00$ & $0.0 \mathrm{E}+00$ & $0.0 \mathrm{E}+00$ & $0.0 \mathrm{E}+00$ & $0.0 \mathrm{E}+00$ & $0.0 \mathrm{E}+00$ & $0.0 \mathrm{E}+00$ \\
\hline Toluene & 3.7E-05 & $0.0 \mathrm{E}+00$ & 4.1E-05 & 1.1E-05 & $0.0 \mathrm{E}+00$ & 3.4E-05 & $0.0 \mathrm{E}+00$ \\
\hline Nonene & $0.0 \mathrm{E}+00$ & $0.0 \mathrm{E}+00$ & $0.0 \mathrm{E}+00$ & $5.9 \mathrm{E}-04$ & $3.2 \mathrm{E}-04$ & $0.0 \mathrm{E}+00$ & 1.3E-03 \\
\hline Nonane & $0.0 \mathrm{E}+00$ & $0.0 \mathrm{E}+00$ & $0.0 \mathrm{E}+00$ & $9.3 \mathrm{E}-04$ & 6.3E-04 & $0.0 \mathrm{E}+00$ & $1.5 \mathrm{E}-03$ \\
\hline Decene & 1.3E-04 & 8.3E-05 & $8.8 \mathrm{E}-04$ & $2.6 \mathrm{E}-03$ & $5.0 \mathrm{E}-03$ & 7.7E-05 & $9.0 \mathrm{E}-03$ \\
\hline Decane & $1.9 \mathrm{E}-03$ & 1.6E-03 & 2.4E-03 & $2.5 \mathrm{E}-03$ & 4.4E-03 & $1.4 \mathrm{E}-03$ & 4.2E-03 \\
\hline Undecene & $0.0 \mathrm{E}+00$ & $0.0 \mathrm{E}+00$ & $6.0 \mathrm{E}-04$ & $1.3 \mathrm{E}-03$ & $3.5 \mathrm{E}-03$ & $9.4 \mathrm{E}-04$ & $2.0 \mathrm{E}-03$ \\
\hline Undecane & $8.6 \mathrm{E}-03$ & 3.3E-03 & $9.0 \mathrm{E}-03$ & $5.5 \mathrm{E}-03$ & 1.3E-02 & $1.3 \mathrm{E}-02$ & 1.1E-02 \\
\hline Dodecene & $0.0 \mathrm{E}+00$ & $0.0 \mathrm{E}+00$ & $0.0 \mathrm{E}+00$ & $0.0 \mathrm{E}+00$ & 1.6E-03 & $1.5 \mathrm{E}-03$ & 1.7E-03 \\
\hline Dodecane & $9.9 \mathrm{E}-01$ & $9.9 \mathrm{E}-01$ & $9.4 \mathrm{E}-01$ & $9.8 \mathrm{E}-01$ & $9.6 \mathrm{E}-01$ & 4.3E-01 & $6.9 \mathrm{E}-01$ \\
\hline Tridecene & $0.0 \mathrm{E}+00$ & $0.0 \mathrm{E}+00$ & $0.0 \mathrm{E}+00$ & $5.9 \mathrm{E}-05$ & $2.8 \mathrm{E}-04$ & $2.9 \mathrm{E}-04$ & 3.2E-04 \\
\hline Tridecane & 1.3E-03 & $2.9 \mathrm{E}-04$ & 1.3E-03 & $6.2 \mathrm{E}-04$ & 1.6E-03 & $2.0 \mathrm{E}-03$ & 1.3E-03 \\
\hline Tetradecene & $0.0 \mathrm{E}+00$ & $0.0 \mathrm{E}+00$ & $5.5 \mathrm{E}-05$ & $5.7 \mathrm{E}-05$ & 4.2E-04 & $2.0 \mathrm{E}-04$ & 4.4E-04 \\
\hline Tetradecane & $0.0 \mathrm{E}+00$ & $0.0 \mathrm{E}+00$ & 3.7E-04 & 3.1E-04 & 1.1E-03 & $9.2 \mathrm{E}-04$ & 9.2E-04 \\
\hline $\begin{array}{c}\text { Gazeification Rate } \\
()\end{array}$ & $0 \%$ & $0 \%$ & $4 \%$ & $1 \%$ & $1 \%$ & $55 \%$ & $28 \%$ \\
\hline Pyrolysis rate () & $1 \%$ & $1 \%$ & $6 \%$ & $2 \%$ & $4 \%$ & $57 \%$ & $31 \%$ \\
\hline
\end{tabular}

In relation to the results given in Figure 2, the fuel mass fraction and the associated pyrolysis products quantification at the reactor's exit are given by RESPIRE as a function of time for each of the SS and Ti cases (Figure $3 \mathrm{a}$ and $3 \mathrm{~b}$ respectively). The oscillations are due to the experimental mass flow rate which is used directly with temperature and pressure measures as boundary conditions. The large production of light species is an indicator of the strong pyrolysis rate and, thus, indirectly of the carbon formation. By comparing both the SS and Ti numerical cases, similar profiles are found (Figure 4). The pyrolysis rate (in wt.\%) is computed for each thermal plateau at the reactor outlet by the unity minus the remaining dodecane mass fraction. The numerical results are closer to those of the experimental Ti case rather than the SS one. Experimentally, the SS case shows a thermal shift of about $50 \mathrm{~K}$ to the right (higher temperature). This means that the pyrolysis activity for the SS reactor is weaker than that of Ti whereas numerically it is the opposite. This confirms that the experimental SS case presents some differences which need to be understood.

In addition, the numerical pyrolysis profiles (i.e. the dodecane mass fraction at each location along the longitudinal coordinate) are given for every isothermal plateau in Figure 5. The maximum rate of conversion shifts from the middle of the SS reactor to the first third when the temperature increases (Figure 5a). This is because the chemical reactions are enhanced by the temperature. This point is 
stronger than the density decrease which corresponds to a velocity rise for constant flow rate. The resulting decrease of the residence time could have shifted the curves to the right if its importance had been higher than the chemistry. Finally, the chemical effect is stronger than the physical one concerning this point specifically. The profiles obtained for the Ti reactor are similar to those of the SS case but they are slightly shifted downstream of the reactor compared to the SS data (Figure 5b). This means that the pyrolysis in the SS reactor is faster than in the Ti one. The SS curve at $823 \mathrm{~K}$ is similar to that at $873 \mathrm{~K}$ with Ti material. This is the same at $973 \mathrm{~K}$ and $1023 \mathrm{~K}$ then at $1023 \mathrm{~K}$ and $1073 \mathrm{~K}$ respectively.
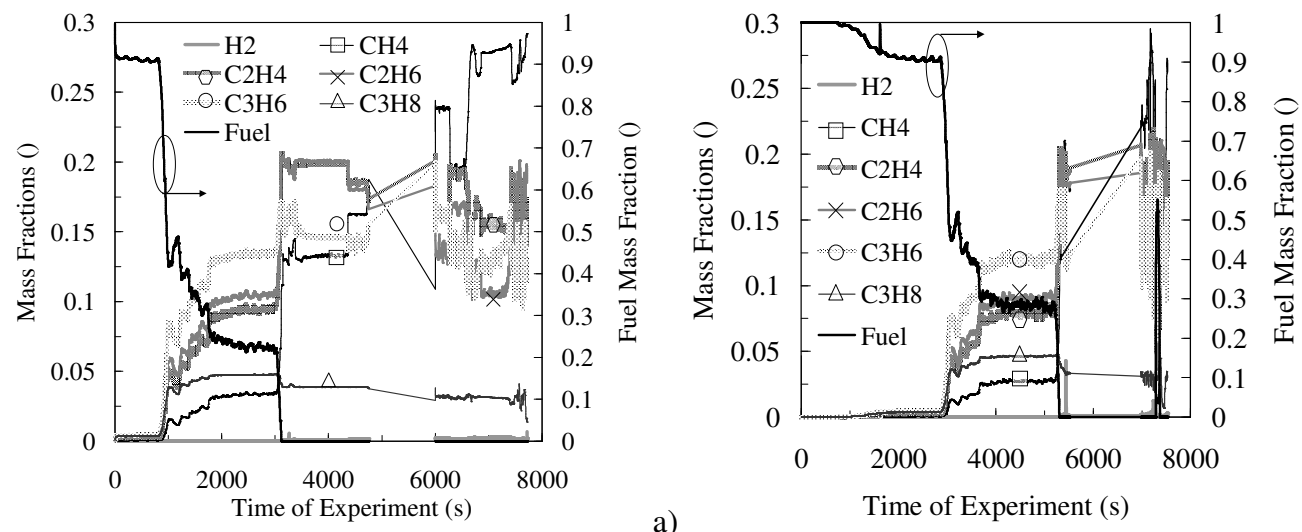

a)

b)

Figure 3. Computed chemical compositions of pyrolysis products: SS case (a) and Ti case (b).

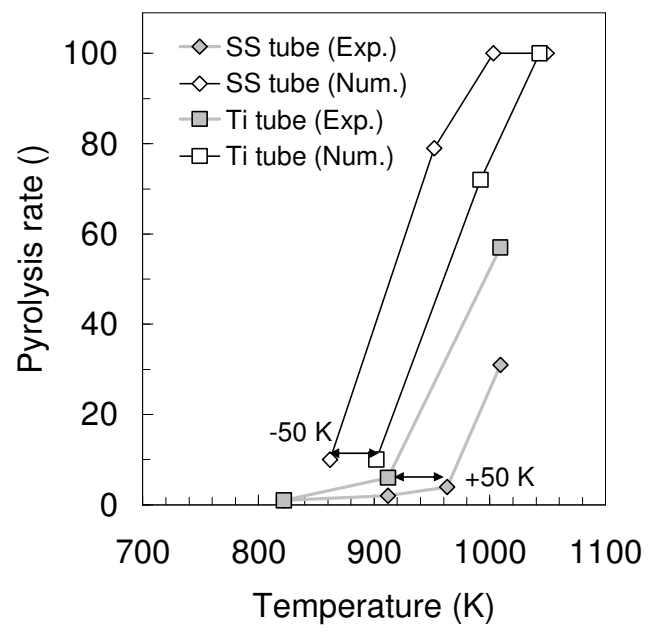

Figure 4. Similarity of both computations and disagreement between simulations and experiments for $\mathrm{Ti}$ and $\mathrm{SS}$ reactors. 

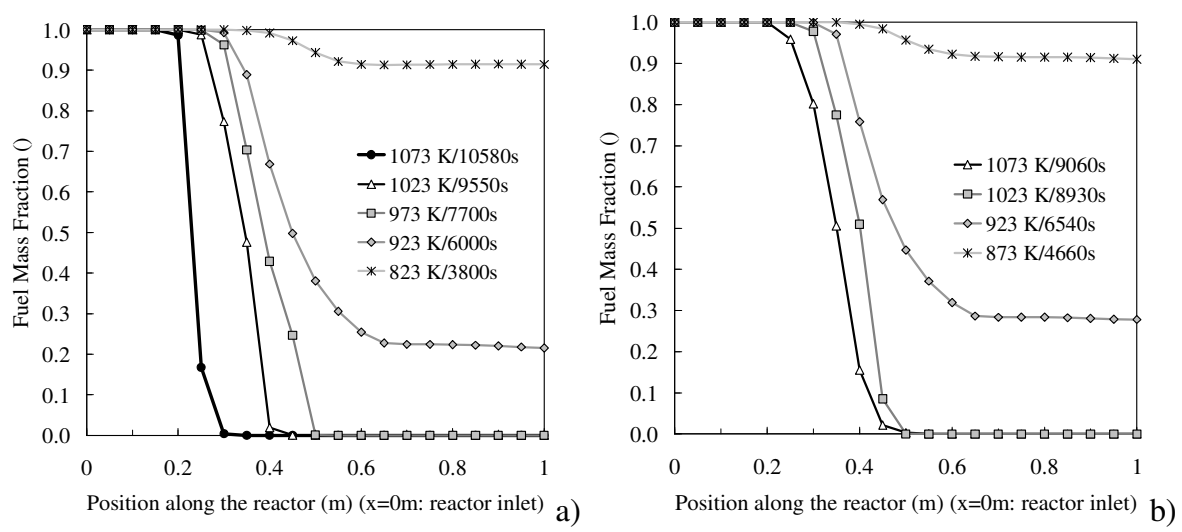

Figure 5. Computed dodecane pyrolysis profiles for each of the thermal plateaus: SS case (a) and Ti case (b)

Due to the heating, the Reynolds number $\left(\operatorname{Re}=(4 . \dot{m}) /\left(\pi \cdot D_{H} \cdot \mu\right)\right)$ increases from $10^{3}$ to $3.10^{5}$ during fuel pyrolysis in the SS reactor (Figure 6a). The data are very similar for the Ti case (Figure 6b). The oscillations on the Reynolds number are due to the representation of the curves and they are not related to time oscillations. They signify that the Reynolds number is for example not linearly linked to the fuel mass fraction. Another parameter impacts its value. When the fuel mass fraction reaches 0 at the reactor outlet, the Reynolds number reaches a value of $1.7 .10^{5}$ for the SS reactor and of $4.29 .10^{5}$ for the Ti reactor for a simulation time of $6000 \mathrm{~s}$ (maximum furnace temperature of $1000 \mathrm{~K}$ as seen in Figure 2a). This can explain why the SS numerical case presents the highest pyrolysis rate because its fluid velocity is lower than that of the Ti case. Consequently, the SS residence time is higher than that of the Ti. This residence time is the total time in the reactor computed by the sum along the longitudinal coordinate over those defined in each mesh cell on the basis of the mean fluid velocity. This fluid flow variation impacts the convective heat transfer coefficient $\left(h=(N u . \lambda) / D_{H}\right)$ which varies from $2000 \mathrm{~W} \cdot \mathrm{m}^{2} \cdot \mathrm{K}^{-1}$ to $4000 \mathrm{~W} \cdot \mathrm{m}^{2} \cdot \mathrm{K}^{-1}$ (Figure 6c) whereas the residence time decreases by $50 \%$. Similar observations can be made for the Ti reactor (Figure 6d). The energy absorbed by the fluid (computed numerically by adding together the heat fluxes received by the fluid in each mesh cell along the longitudinal coordinate)

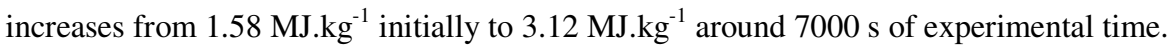



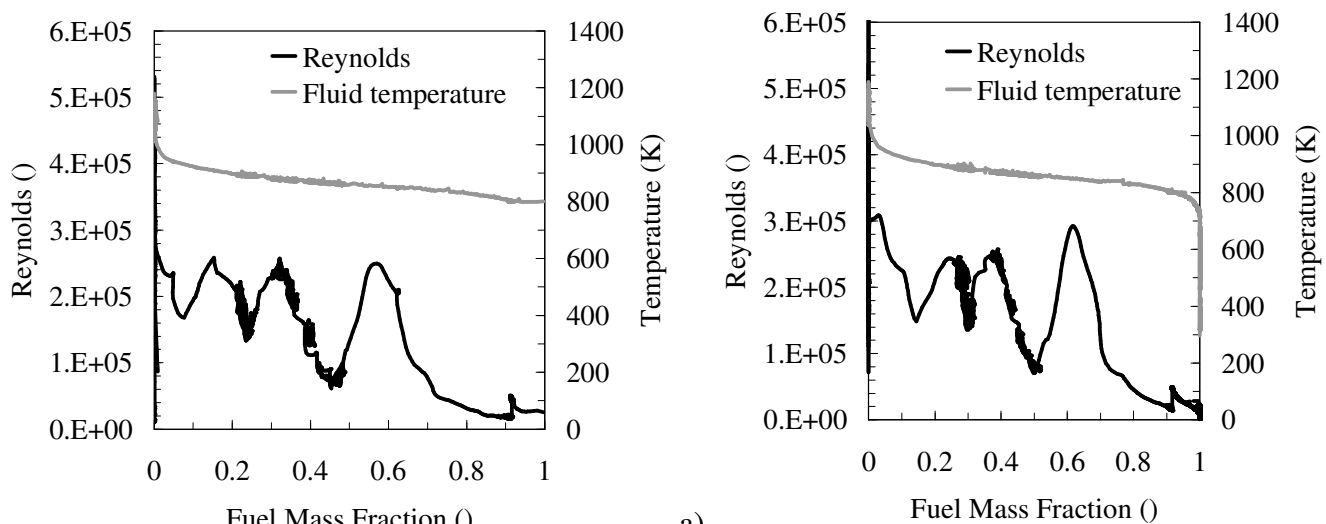

a)

b)
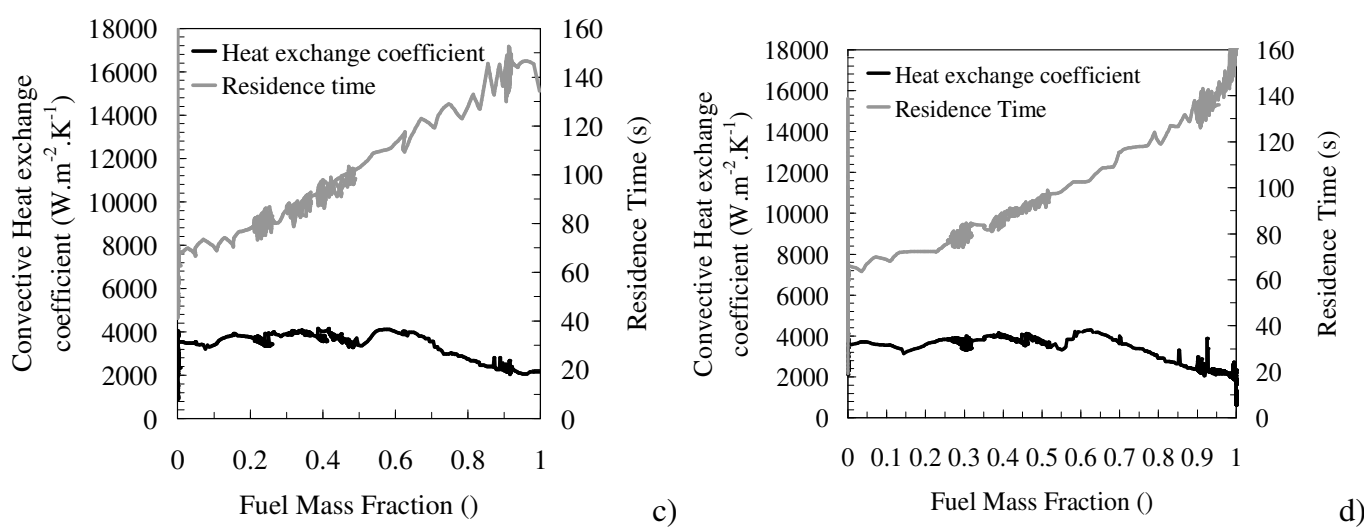

Figure 6. Heat and mass transfer characteristics as a function of remaining dodecane mass fraction at the process outlet for: the SS case (a,c) and the Ti case (b,d).

To conclude on this first comparison, it is difficult to explain the differences observed between the Ti and SS cases. Moreover, the numerical results show a higher pyrolysis for SS than for Ti, whereas the opposite is found experimentally. Consequently, it can be assumed that there is a missing parameter in the numerical work to account for the differences observed experimentally between the two reactor types.

\section{B. Effect of the reactor material type}

In order to investigate the intrinsic effect of the physical properties of the reactor material, the properties of the stainless steel (Table 2) have been replaced numerically in the code by those of titanium (Table 2). No other modifications on catalytic effect for example have been made so as to allow the impact of the physical properties, such as the thermal diffusivity, to be strictly observed. The computational results related to the time $6000 \mathrm{~s}-7700 \mathrm{~s}$ are presented for the initial SS case and the new modified one (Figure 7). The Reynolds number is the maximum one computed along the reactor as a 
function of time and the mass fractions of pyrolysis products (methane and ethylene) are found at the reactor outlet. The oscillations are physically due to the non stabilized mass flow rate whose experimental values are used directly as boundary conditions in the RESPIRE code. The reactor material type is of minor importance on heat and mass transfer, such as demonstrated by the Reynolds number (Figure 7a), and this is confirmed by looking at the chemistry (Figure 7b). Indeed, despite the oscillations, the Reynolds and chemical profiles for both cases are almost overlapping. Consequently, the discrepancies observed experimentally between the SS and Ti cases are due to a phenomenon other than that of the physical properties of the reactors. Because of strong differences previously observed on coke formation [9], we have chosen to study this carbon deposit and its related effect on the system.

Table 2. Comparison of SS and Ti material properties.

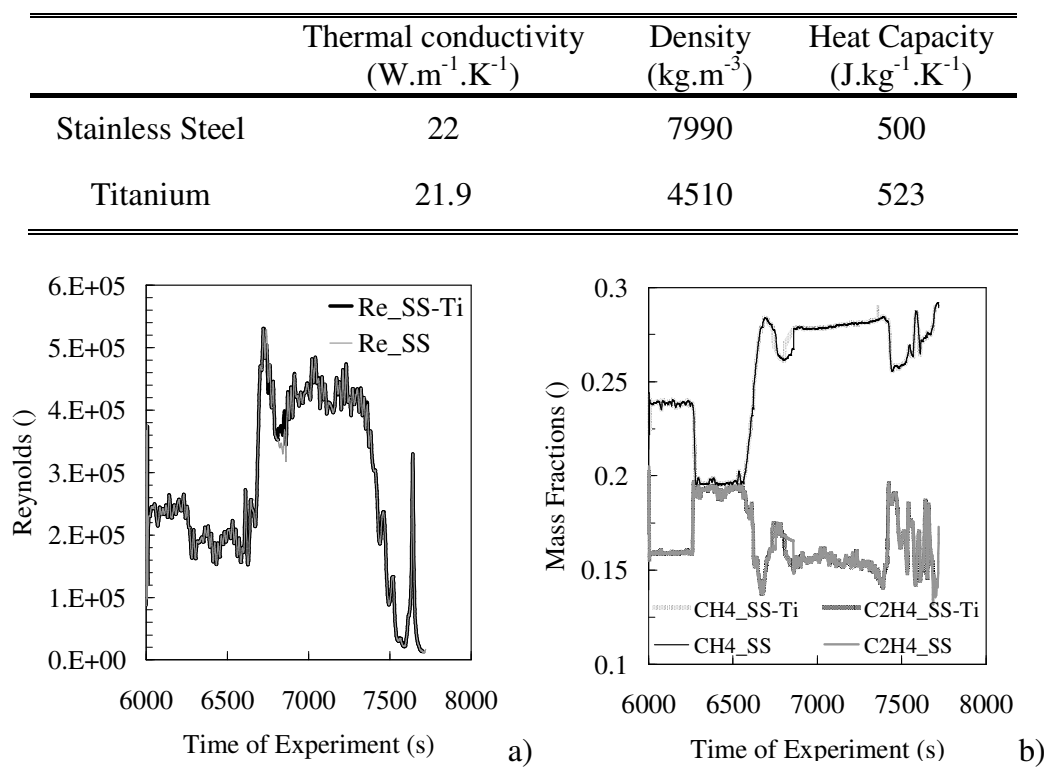

Figure 7. Absence of effect of reactor's physical properties on computed maximum Reynolds number (a) and outlet chemical composition (b).

\section{Effect of coke formation on heat transfer}

The coke formation is computed as presented in section II.A. For a first step (this section only), the reduction of the flow cross-section is not taken into account. This means that the coke only acts as a thermal insulator. The uniform coke layer thickness computed as a function of time is given with the fuel flow rate measured experimentally and serving as boundary condition for the computation (Figure 8a). The maximum temperatures found along the reactor are given as a function of time for the initial SS test 
case and for the present coking case (Figure 8b). The $10^{8} \mathrm{~K} . \mathrm{s}^{2}$ criterion presented in section II.A. is reached at around $5350 \mathrm{~s}$ during a furnace temperature setup increase (Figure 8a). The coke thickness rapidly increases to $1.27 \mathrm{~mm}$ (Figure $8 \mathrm{a}$ ). Then, it stabilizes around this value because the temperature increase is accompanied by a residence time decrease and, as a result, their product is below the criterion. This is interesting because it is related to the dynamic of the processes. The convection and radiation heat transfers are faster than the fluid flow stabilization. At around $7450 \mathrm{~s}$, again, the criterion is reached and the coke layer reaches about $3.7 \mathrm{~mm}$ (Figure 8a), which is more than the radius of the tubular reactor that is to say $2.175 \mathrm{~mm}-$. As a consequence, the test can be considered as finished because the reactor is completely clogged. This sudden coke thickness increase corresponds exactly to the experimental mass flow decrease (Figure 8a). The calculations are in agreement with the experiments. The thermal discrepancy observed on the internal wall temperature between this case and the original SS case is below $0.2 \mathrm{~K}$ (Figure $8 \mathrm{~b}$ ). The coke-fluid interface temperature and the coke-reactor contact temperature of this new simulation case are both very close to the fluid-reactor interface temperature of the original SS case. The thermal effect of the carbon layer is thus negligible. Consequently, if the coke formation is responsible for the differences observed experimentally between the SS and Ti cases, this is not due to its thermal effect. The hydraulic effect by cross-section reduction will be investigated (next section).
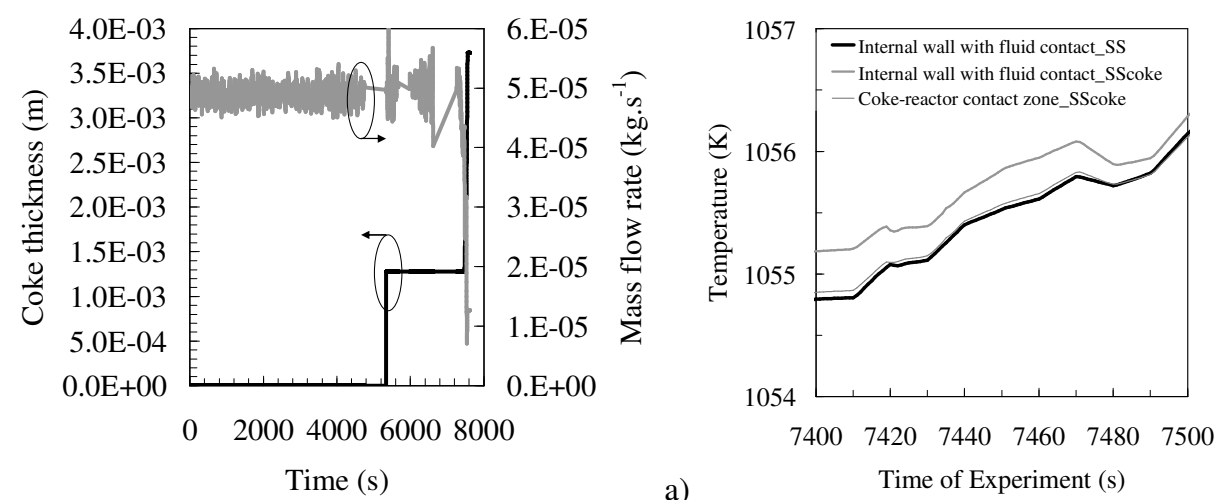

Figure 8. Numerical coke thickness increase and reactor clogging with experimental validation (a) and minor effect of the coke formation on heat transfer (b).

\section{Coke effect on both fluid mechanics and heat transfer}

The coking activity is determined as presented in the previous section. Its effect on the fluid flow is now considered through the geometrical changes (reduction of fluid flow cross-section). This impacts all the other parameters such as the Reynolds number and the convective heat transfer coefficient. The 
Reynolds number computed along the reactor (Figure 9a) is given for initial and new test cases under stabilized conditions within two thermal plateaus. The total residence time in the reactor is given as a function of the experimental time for the original case and for the new coking case (Figure 9b). For the latest case, the computed cross-section, which is reduced due to coke formation, is also given as a function of time (Figure 9b). Strong discrepancies now appear between the original SS case and this new simulation case with full consideration of the coke formation (Figure 9). Before the apparition of carbon deposits for a furnace temperature set point of $973 \mathrm{~K}$, the same Reynolds number profile is found in the reactor (Figure 9a). When increasing the temperature to $1023 \mathrm{~K}$, the Reynolds number is higher for the full coking case at the beginning of the reactor (a factor two is found at around $0.2 \mathrm{~m}$ ) but it is much lower at the outlet than the initial case (one order of magnitude). This is attributed to the rapid reduction of the flow cross-section which is divided by a factor of 4 in $200 \mathrm{~s}$ (Figure $9 \mathrm{~b}$ ). This shows the rapidity of the coking phenomenon which has largely been observed experimentally [9]. As a consequence, the total residence time in the process is dramatically decreased (up to a factor 5) when considering the section reduction because of the fluid velocity increase (Figure 9b). It is interesting to note that the local Reynolds number increase at around $0.3 \mathrm{~m}$ and the local decrease around the exit of the reactor both lead to a general decrease of the residence time. This is because of the residence time distribution in the reactor. The fluid spends about $80 \%$ of the total residence time in the first half of the reactor and only 10 $\%$ in the last third. As a consequence, the Reynolds variation in the first half of the process has a major impact on the residence time compared to other variations near the outlet.

Through the decrease of the residence time, the pyrolysis process is now slower for this full simulation case compared to the original SS case. The experimental trend found on the SS case in comparison with the Ti case in Figure 4 is now explained. It is confirmed by the absorbed mass energy which is lower for the full case in case of coke formation (Figure 10). Up to a factor 3 on the absorbed energy is found and this clearly drives the fluid pyrolysis. The implication of the coking activity through the modification of fluid flow is a major result because it helps to understand the pyrolysis phenomena involving chemistry and heat and mass transfers.

In addition, the chemical composition at the reactor outlet has been compared to these two cases with and without coke formation. For the thermal plateau corresponding to a furnace temperature of around $1073 \mathrm{~K}$ for example, the results at the reactor exit show that the ratio of $\mathrm{H}$ atoms over $\mathrm{C}$ atoms is slightly 
higher in case of coking formation (1.732 with, compared to 1.726 without coke). This is qualitatively in agreement with the solid carbon deposit formation since the fluid which reaches the reactor exit should be more hydrogenated in case of coke formation. It is also interesting to note that the initial $\mathrm{H} / \mathrm{C}$ ratio of dodecane is 2.17 and that the mean one of all the considered species in the detailed pyrolysis mechanism is 1.89 (it is 2 for the alkenes). The decrease of the molecular weight due to pyrolysis (divided by about a factor of 3) at the process outlet also corresponds to a decrease of the $\mathrm{H} / \mathrm{C}$ ratio, which is due to the increase of the concentration of aromatic compounds,such as benzene (H/C ratio equal to 1$)$.
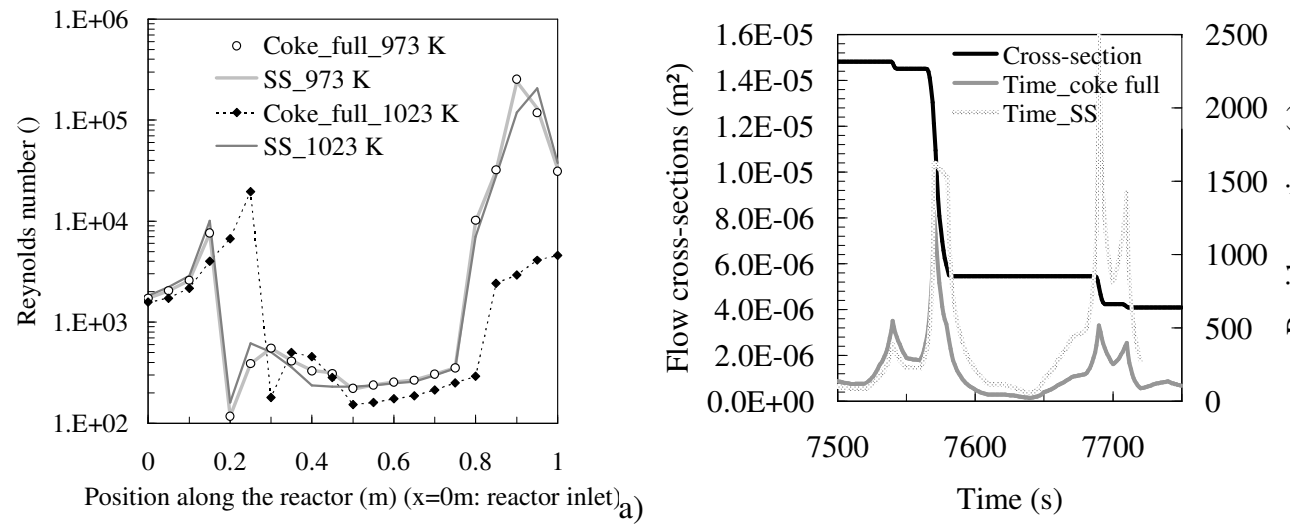

b)

Figure 9. Hydraulic effect of coking formation (a) due to reduction of flow cross-section (b)

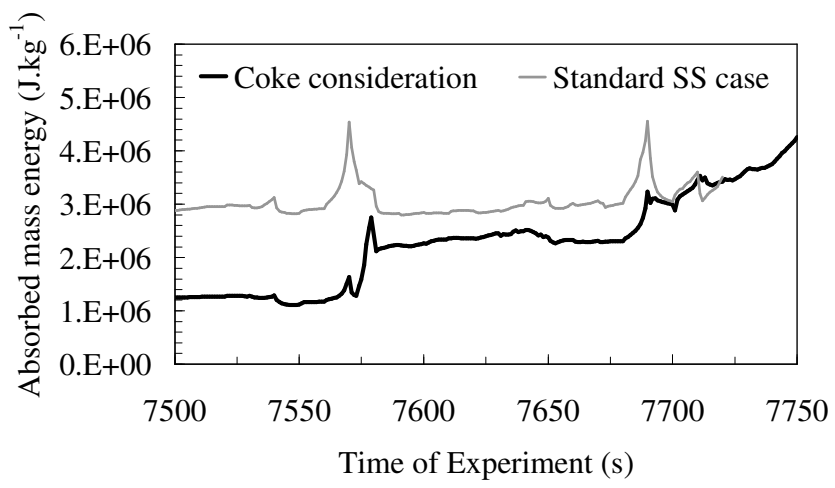

Figure 10. Energy by mass unit absorbed by the reactive fluid during the test with and without coke consideration.

\section{Conclusion}

Fuel pyrolysis is encountered in a wide variety of applications such as active and regenerative cooling, steam cracking and petrochemical plants. The formation of coke is one of the major chemical phenomena. It is coupled with heat and mass transfer and catalytic effect of the reactors. Dodecane pyrolysis has been 
achieved experimentally at $6 \mathrm{MPa}$ and $50 \mathrm{mg} . \mathrm{s}^{-1}$ within two kinds of reactors: stainless steel and titanium. The conversion rate is higher with titanium. To decouple the thermal effect (due to the modification of physical properties between both materials) and the catalytic effect (heterogeneous reactions), a numerical study has been conducted since this parameter-splitting strategy is not possible experimentally. Numerical simulations showed a higher pyrolysis rate for the SS tube than for the Ti ones, as opposed to the experiment. The effect of the reactor's physical properties is negligible. The coking activity has been modeled to observe the growth of the carbon layer. Its insulation effect in case of perfect contact with the reactor is of minor impact. The reduction of flow cross-section is demonstrated to be an important parameter. The related maximum Reynolds number rises by a factor of 4 and the absorbed energy by a factor of 3 due to fluid velocity increase (residence time decreased by a factor of 4). As a consequence, the pyrolysis of the fluid is lower considering the entire coupling of multiphysics phenomena with coke formation than omitting the carbon layer effect. The sequence of events is demonstrated to be the following: the catalytic effect of the SS reactor and its surface effect make the carbon deposit to stick to the wall, this reduces the cross-section, it accelerates the fluid and decreases the residence time, and thus the convective heat transfers and the related fuel pyrolysis. A finer analysis of the catalytic effect with heterogeneous reactions will now be considered to estimate how this impacts the coke adhesion.

\section{Acknowledgments}

The authors want to quote the COMPARER team and especially Guillaume Fau from PRISME laboratory and Marc Bouchez from MBDA France. The present work was performed with the contribution of the city of Bourges, of the "Conseil Général du Cher", of the "Conseil Régional du Centre", of the FRED, of the FEDER, of the FSE, of MBDA-France and of Y. Parmantier.

\section{References}

[1] Fry, R S, 2004, A century of ramjet propulsion technology evolution, J. Prop. Power, Vol. 20 (1).

[2] Griggs, S.C., Haji-Sheikh, A., Parametric Study of Actively Cooled Aircraft Structure, Journal Of Thermophysics And Heat Transfer, Vol. 12, No. 3, July- September 1998

[3] Amar, A.J., Blackwell, B.F., Edwards, J.R., Development and Verification of a One-Dimensional Ablation Code Including Pyrolysis Gas Flow, Journal Of Thermophysics And Heat Transfer, Vol. 23, No. 1, January-March 2009 
[4] Kuntz, D.W., Hassan, B., Potter, D.L., Predictions of Ablating Hypersonic Vehicles Using an Iterative Coupled Fluid/Thermal Approach, Journal Of Thermophysics And Heat Transfer, Vol. 15, No. 2, April-June 2001

[5] Bouchez, M., Cheuret, F., Grenard, P., Redford, J.A., Sandham, N.D., Roberts, G.T., Passaro, A., Baccarella, D., Dalenbring, M., Smith, J., 2008, Material-Aero-Thermal Interaction Computations in the ATLLAS European Programme, AIAA paper, 4670.

[6] Wang, Y.Z., Hua, Y.X., Meng, H., Numerical Studies of Supercritical Turbulent Convective Heat Transfer of Cryogenic-Propellant Methane, Journal Of Thermophysics And Heat Transfer, Vol. 24, No. 3, July-September 2010

[7] Urbano, A. and Nasuti, F., Numerical Analysis of Heated Channel Flows by a Space-Marching Finite Volume Technique, Journal Of Thermophysics And Heat Transfer, Vol. 25, No. 2, AprilJune 2011

[8] Steelant, J., 2008, ATLLAS: Aero-Thermal Loaded Material Investigations for High-Speed Vehicles, AIAA paper, 2582.

[9] Gascoin, N., 2010, Etude et mesure de paramètres pertinents dans un écoulement réactif application au refroidissement par endo-carburant d'un super-statoréacteur, First Ed., Editions Universitaires Européennes.

[10] Gascoin, N., Gillard, P., Bernard, S., Bouchez, M., 2008a, Characterisation of coking activity during supercritical hydrocarbon pyrolysis, Fuel Process Technol., vol. 89, 1416-1428.

[11] Garcia-Dopico, M., Garcia, A., Santos Garcia, A., 2006, Modelling coke formation and deactivation in a FCCU, Applied Catalysis A: General, vol. 303 (2), 245-250.

[12] Guéret, F., Billaud, F., Fixari, B., Le Perchec, P., 1995, Thermal coupling of methane, experimental investigations on coke deposits, Carbon, vol. 33, 159-170.

[13] Albright, L.F., McConnell, C.F., Welther, K., 1978, Types of coke formed during the pyrolysis of light hydrocarbons, ACS, vol. 23.

[14] Lucas, P. and Marchand, A., 1990, Pyrolytic carbon deposition from methane: an analytical approach to the chemical process, Carbon, vol. 28, 207-219. 
[15] Benzinger, W., Becker, A., Hüttinger, K., 1996, Chemistry and kinetics of chemical vapour deposition of pyrocarbon: I. Fundamentals of kinetics and chemical reaction engineering, Carbon, vol. 34, 957-966.

[16] Becker A. and Hüttinger K., 1998, Chemistry and kinetics of chemical vapor deposition of pyrocarbon-IV pyrocarbon deposition from methane in the low temperature regime, Carbon, vol. 36, 213-224.

[17] Soares Cerqueira, H., Chalbaud Biscaia, E. Jr., Falabella Sousa-Aguiar, E., 1997, Mathematical modeling and simulation of catalytic cracking of gasoil in a fixed bed: Coke formation, Applied Catalysis A: General, vol. 164 (1-2), 35-45.

[18] Caeiro, G., Magnoux, P., Lopes, J.M., Lemos, F., Ramoa Ribeiro, F., 2006, Kinetic modeling of the methylcyclohexane transformation over H-USY: Deactivating effect of coke and nitrogen basic compounds, Journal of Molecular Catalysis A: Chemical, vol. 249 (1-2), 149-157.

[19] Albright, L.F. and Marek, J.C., 1988, Coke formation during pyrolysis: Roles of residence time, reactor geometry, and time of operation, Industrial \& engineering chemistry research, vol. 27, 743751.

[20] Gascoin, N., Gillard, P., Bouchez, M., 2009, Characterization of Supercritical Reactive Flow for Hypersonic Real-Time Application, AIAA paper, 7375.

[21] Gascoin, N, Gillard, P, Dufour, E, Touré, Y, 2007, Validation of transient cooling modeling for hypersonic application, Journal Of Thermophysics And Heat Transfer, Vol. 21 (1), 86-94.

[22] Gascoin, N., Gillard, P., Bernard, S., Daniau, E., Bouchez, M., 2008, Pyrolysis of Supercritical Endothermic Fuel: Evaluation for Active Cooling Instrumentation, International Journal of Chemical Reactor Engineering, vol. 6, A7.

[23] Gascoin, N., Abraham, G., Gillard, P., 2010, Synthetic and jet fuels pyrolysis for cooling and combustion applications, J. Anal. Appl. Pyrol., vol. 89, 294-306.

[24] Dahm, K.D., Virk, P.S., Bounaceur, R., Battin-Leclerc, F., Marquaire, P.M., Fournet, R., Daniau, E., Bouchez, M., 2004, Experimental and modelling investigation of the thermal decomposition of n-dodecane, J. Anal. Appl. Pyrol., vol. 71, 865-881.

[25] Mohamadalizadeh, A., Towfighi, J., Karimzadeh, R., 2008, Modeling of catalytic coke formation in thermal cracking reactors, Journal of Analytical and Applied Pyrolysis, vol. 82 (1) 134-139. 
[26] Kern, C. and Jess, A., 2005, Regeneration of coked catalysts--modelling and verification of coke burn-off in single particles and fixed bed reactors, Chemical Engineering Science, vol. 60 (15), 4249-4264.

[27] Beyne, A.O.E., Froment, G.F., 1990, A percolation approach for the modeling of deactivation of zeolite catalysts by coke formation, Chemical Engineering Science, vol. 45 (8), 2089-2096.

[28] Guo, Z. and Tang, H., 2005, Numerical simulation for a process analysis of a coke oven, China Particuology, vol. 3 (6), 373-378.

[29] Manafzadeh, H., Sadrameli, S. M., Towfighi, J., 2003, Coke deposition by physical condensation of poly-cyclic hydrocarbons in the transfer line exchanger (TLX) of olefin plant, Applied Thermal Engineering, vol. 23 (11), 1347-1358.

[30] Souza, B.A., Matos, E.M., Guirardello, R., Nunhez, J.R., 2006, Predicting coke formation due to thermal cracking inside tubes of petrochemical fired heaters using a fast CFD formulation, Journal of Petroleum Science and Engineering, vol. 51 (1-2), 138-148.

[31] Herbinet, O., Marquaire, P.M., Battin-Leclerc, F., Fournet, R., Thermal decomposition of ndodecane: Experiments and kinetic modeling, Journal of Analytical and Applied Pyrolysis, Volume 78, Issue 2, March 2007, Pages 419-429.

[32] Guo, X.Q., Sun, C.Y., 2001, Equation of State Analog Correlations for the Viscosity and Thermal Conductivity of Hydrocarbons and Reservoir Fluids, J. Petrol Sci Eng, vol. 30, 15-27.

[33] Abraham, G., Gascoin, N., Gillard, P., Bouchez, M., 2011, Real-time method for the identification and quantification of hydrocarbon pyrolysis products: Part I. Development and validation of the Infra Red technique, Journal of Analytical and Applied Pyrolysis, 10.1016/j.jaap.2011.03.014.

[34] Gascoin, N., Abraham, G., Gillard, P., Bouchez, M., 2011, Real-time method for the identification and quantification of hydrocarbon pyrolysis products: Part II. Application to transient pyrolysis and validation by numerical simulation., Journal of Analytical and Applied Pyrolysis, 10.1016/j.jaap.2011.04.005 